\title{
METÁFORAS OCULTAS EN LOS ESPACIOS DE LA MUERTE ACTUALES
}

\author{
Antonia Pérez Naya \\ Hidden metaphors in current death spaces \\ Boletín Académico. Revista de investigación y arquitectura contemporánea \\ Escuela Técnica Superior de Arquitectura. Universidade da Coruña \\ elSSN 2173-6723 \\ www.boletinacademico.com \\ Número 3 (2013) \\ Páginas 29-36 \\ Fecha de recepción 29.10.2012 \\ Fecha de aceptación 23.01.2013
}

https://doi.org/10.17979/bac.2013.3.0.994

\section{Resumen}

Los espacios funerarios tradicionalmente contienen variados catálogos de imágenes simbólicas que trasmiten mensajes reconocidos por el colectivo social. Por el contrario, en los actuales, ya no limitados exclusivamente a los cementerios, se percibe un enfoque más contenido y aséptico, con metáforas ocultas apenas perceptibles, reinterpretadas desde la perspectiva de la muerte actual. Testimonio evidente de que la arquitectura es un claro reflejo y una consecuencia directa de la sociedad que la genera.

\section{Abstract}

The funerary spaces traditionally contain various symbolical image catalogues that convey messages recognized by the society at large. On the contrary, the current approach, which is not limited exclusively to cemeteries, is much more limited and aseptic, with hidden metaphors which are barely discernible and reinterpreted from the current view of death. This is a clear testimony that architecture is a clear reflection and a direct consequence of the society that creates it.

\section{Palabras clave}

Arquitectura, Metáfora, Símbolo, Cementerio, Crematorio

\section{Keywords}

Architecture, Metaphor, Symbol, Cemetery, Crematory 


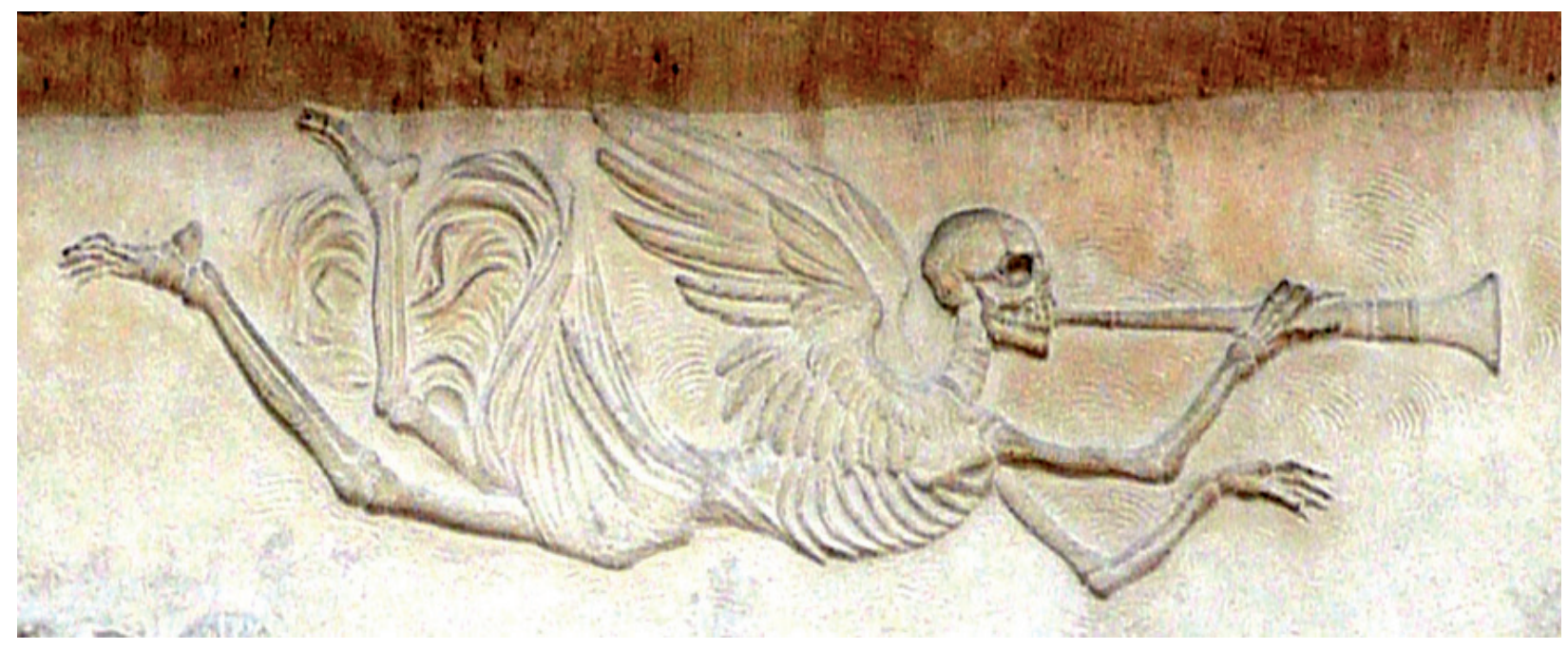

1 Detalle de tumba en el cementerio Père Lachaise, París

\section{OBJETIVO}

El presente artículo surge de una investigación centrada en los aspectos simbólicos y metafóricos de las arquitecturas derivadas de la muerte, y de la profunda transformación que en los últimos tiempos se observa en las mismas. Hasta mediados del siglo XX, se trataba de espacios repletos de signos, ratificados culturalmente, que contribuían a singularizarlos, dotándolos de una acusada identidad que permitía reconocerlos de inmediato, lo que no sucede en la mayoría de los edificios funerarios diseñados en la actualidad. Una lectura más profunda de los mismos demuestra que, a pesar de su supuesto pragmatismo alejado de un talante ritual, en su proceso creativo subyacen metáforas y poéticas ocultas que demuestran una sensibilidad especial por parte de sus autores ante este tipo de espacios.

El objetivo de este artículo es demostrar cómo las nuevas arquitecturas funerarias, a pesar de no significarse con iconografías evidentes, son proyectadas con un espíritu y con un respeto que las singulariza, utilizando un particular lenguaje arquitectónico, aparentemente alejado del tradicional en la forma, aunque no tanto en el fondo.

Para argumentar lo anterior podrían citarse obras como el crematorio, no construido, de Bergaliden de S. Lewerentz (1914), concebido desde la óptica de un recorrido ritual iniciado en el atrio de la muerte y finalizado en el templo de la memoria; el del cementerio del Bosque de Estocolmo de G. Asplund (1940), que incide en el dramatismo de la sala de incineración a modo de gran cámara funeraria; o el crematorio de Skövde (1937), del mismo autor, con intensas connotaciones vernáculas. Igualmente se consideraron obras más actuales como el crematorio de Nakatsu de Fumihiko Maki (1997), caracterizado por su austeridad y circunspección, o el crematorio en Heimolen de Claus en Kaan (2009), que separa el ritual de despedida del espacio de cremación.

Finalmente se han seleccionado el crematorio Treptow, de Axel Schultes y Charlotte Frank, y el crematorio de Kakamigahara, de Toyo Ito. La razón de esta elección radica en la intención de contrastar y enfrentar dos arquitecturas pensadas para la misma función, pero con actitudes y sensibilidades aparentemente muy distintas, lo que parece demostrar conductas y disposiciones ante la muerte —entre lo espiritual de Oriente y lo racional de Occidente- que se mantienen diferentes a lo largo de los siglos.

\section{El LENGUAJE TRADICIONAL DE LA MUERTE}

En nuestra cultura actual, todas las expresiones artísticas son lenguajes, formas de comunicación simbólicas, a través de las cuales interpretamos y entendemos el mundo. Para representar y expresar lo que nos rodea, recurrimos continuamente a signos y a símbolos que nos remiten a cuestiones de carácter íntimo o espiritual difíciles de expresar con inmediatez. De ahí deriva el reconocimiento por parte de todas las civilizaciones del poder de los símbolos; se puede señalar que constituyen un lenguaje universal que ha sido utilizado a lo largo del tiempo en todas las artes y sociedades ${ }^{1}$. 

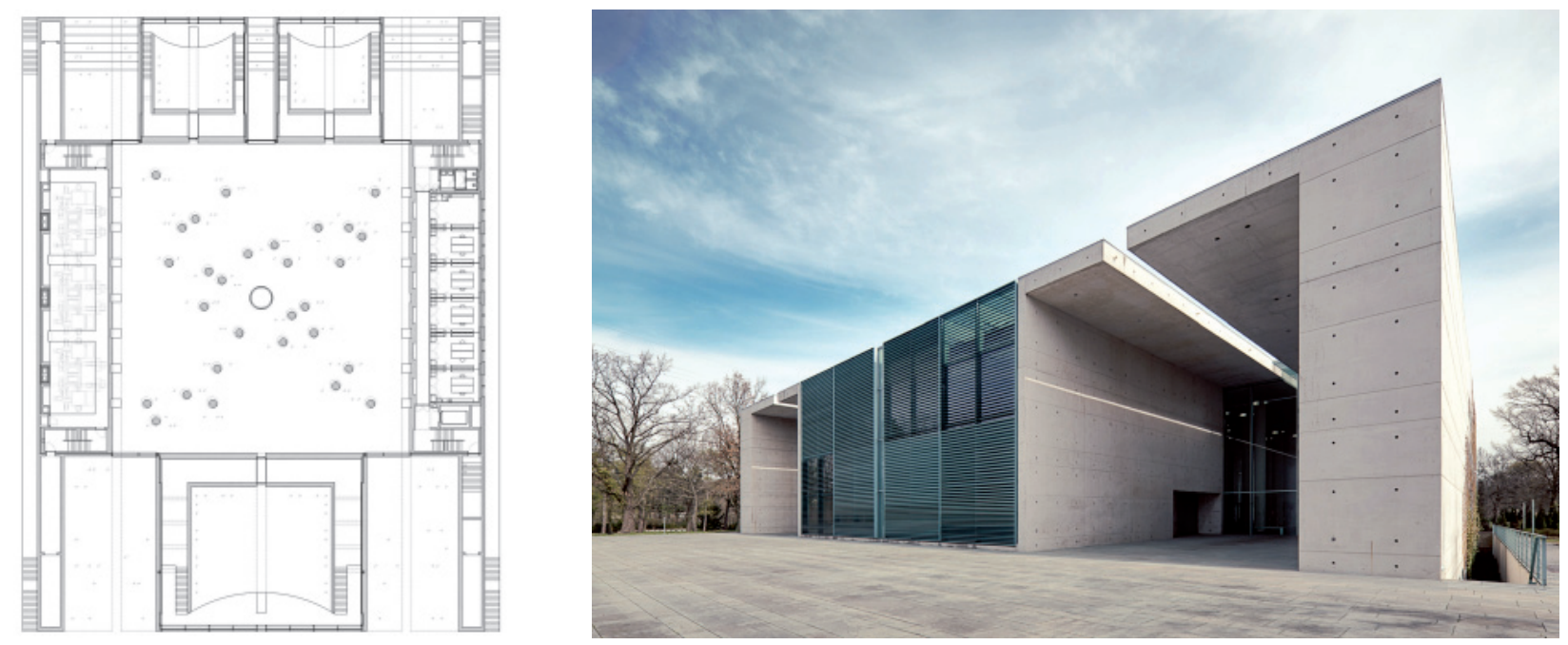

2-3 Axel Schultes y Charlotte Frank, crematorio Treptow, Berlín, 1996-1998. Planta de situación (izda.) y vista exterior (dcha.)

Establecen un modo de comunicación al servicio de una determinada cultura. En palabras de M. Eliade, «la presencia de las imágenes y de los símbolos es lo que conserva 'abiertas' a las culturas [...] gracias a ellas pueden comunicarse las diversas historias $»^{2}$. De esta manera, en nuestro recuerdo permanecen recopiladas imágenes e iconografías que constituyen signos heredados culturalmente de todo aquello que no es transitorio. Su utilización como medio de comunicación se incrementa ante situaciones - como tratar de comprender y asumir la muerte- que desconciertan y perturban profundamente al ser humano (Fig. 01).

Cuando hablamos de símbolos y de metáforas en la arquitectura $-\mathrm{y}$ concretamente en la arquitectura funeraria - nos referimos a las imágenes evocadoras que trasmiten mensajes identificados por el colectivo social. Debiendo diferenciar el símbolo, que siempre solicita la interpretación intelectual de un símil, de la metáfora, que lo que busca es estimular la sensibilidad ${ }^{3}$.

No es posible interpretar la arquitectura únicamente desde una perspectiva utilitaria, funcional o morfológica, ya que los espacios arquitectónicos se transforman en «receptáculos de símbolos» ${ }^{4}$ de gran alcance alegórico ligados a determinadas tipologías arquitectónicas.

En todos los cementerios decimonónicos encontramos un variado inventario de iconografías con connotaciones de carácter religioso, de identidad y metafóricas, que contribuyen a significar estos recintos dotándolos de carácter sacro, no necesariamente religioso ${ }^{5}$. Un rico conjunto de simbolismos repletos de significados con una traducción compleja, puesto que algunas de las iconografías que representan la muerte carecen de particularidades intrínsecas que les otorgue este carácter. Éste le es concedido por la percepción y el sentimiento social.

\section{LENGUAJE DE LA MUERTE ACTUAL}

Los últimos años han sido testigos de profundos cambios en la actitud ante la realidad de la muerte, resultado de los avances tecnológicos, científicos y del creciente proceso de secularización. La muerte formó parte durante siglos de la experiencia vital, lo que no sucede en la actualidad, con un modo de vivir ligado a lo material, al individualismo y alejado de lo trascendente. Todas estas cuestiones repercuten en los rituales fúnebres gestionados por profesionales no adscriptos a ningún credo, y como consecuencia, en la redefinición de los espacios arquitectónicos donde se celebran, que se encuentran en un momento de transformación e innovación.

Hasta hace poco tiempo, el espacio funerario por excelencia era el cementerio.Sin embargo, la sociedad actual ha ido demandando nuevos programas de necesidades, derivados de las presentes funciones que han dado lugar a los tanatorios, lugares de acompañamiento, velatorio y despedida, o los crematorios, resultado de la proliferación de incineraciones. Estos últimos suponen un interrogante ante el concepto tradicional de la tumba como huella del desaparecido, y por extensión, del cementerio como lugar de visita, implicando el escepticismo de una sociedad frente a ideas como la muerte antesala de la vida eterna, asociadas 


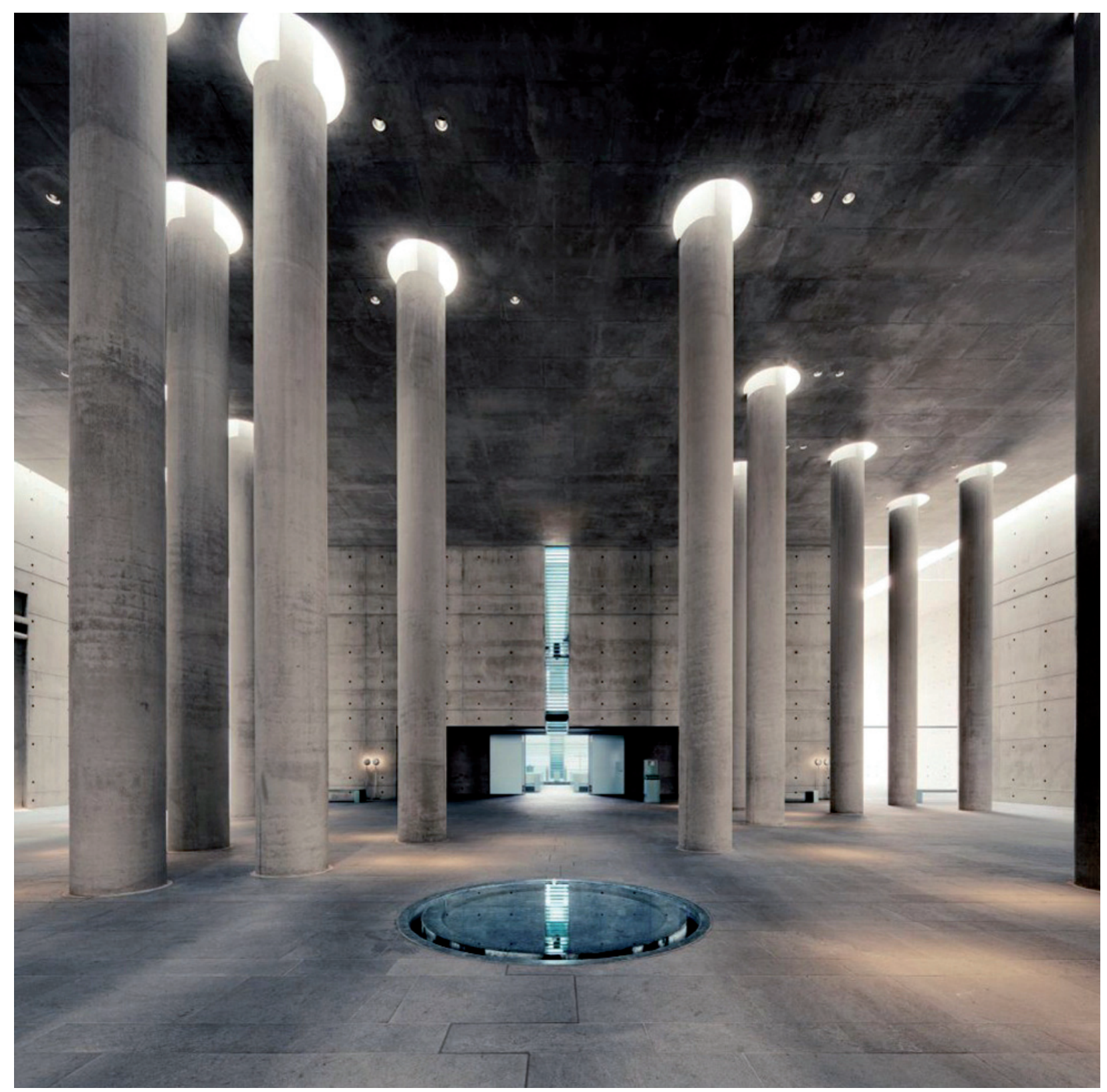

4 Axel Schultes y Charlotte Frank, crematorio Treptow, Berlín, 1996-1998. Vista de la sala de la Condolencia

sobre todo a la tradición católica. En referencia a esto afirma Nigel Barley: «En nuestro modelo de consumo ostentoso, el cuerpo de usar y tirar se convierte en un problema más de residuos cuya solución reside en la incineración industrial, la pulverización o_—es lo más correcto ecológicamente_- el reciclaje_(...) la idea de la buena muerte va desapareciendo al ser sustituida por la de la muerte apropiada ${ }^{6}$. Por estas razones, tanatorios y sobre todo crematorios, se están convirtiendo en la alternativa de nuestra época al cementerio tradicional.

En las actuales arquitecturas funerarias se acusa el distanciamiento de la muerte antes mencionado; evidencia de esta afirmación es la utilización más contenida y sintetizada de imágenes evocativas. Han descendido los motivos de carácter doctrinal, y subyacen escondidos los motivos de carácter metafórico, sintomático de la progresiva secularización social y de los cambios de pensamiento.

Los asépticos y neutros espacios de la muerte actuales, totalmente desinfectados de símbolos que los identifiquen como tales, demuestran, una vez más, cómo la arquitectura es inseparable de la sociedad que la genera. La mayoría de las arquitecturas funerarias del siglo XXI están concebidas sin condicionamientos previos impuestos por un credo en particular. Se consideran como una infraestructura o un servicio público más, que al presentar lenguajes ambiguos, pueden ser confundidas con cualquier otro equipamiento de carácter colectivo. 
De todos modos, analizándolas con detenimiento, se detecta que no han perdido parte del carácter sagrado de otros tiempos. En la práctica totalidad de las culturas se sacralizan y se respetan los espacios de la muerte, por lo que no es posible dar la espalda a una herencia cultural con una religiosidad que forma parte de la conciencia social que, al menos inconscientemente, determina ciertos comportamientos. Puesto que, como afirma Mircea Eliade, una existencia profana jamás se vive en estado puro: "Cualquiera que sea el grado de desacralización del mundo (...) el hombre que opta por una vida profana no logra abolir del todo el comportamiento religioso ${ }^{7}$.

Por eso las arquitecturas relacionadas con la muerte se abordan con una sensibilidad especial. No se trata de arquitecturas constructoras de escenarios de vida, sino constructoras de escenarios de evocación y memoria. Los espacios funerarios deben de actuar como recintos albergadores de sentimientos y emociones como la tristeza, los recuerdos, los sueños o la nostalgia, que constituyen la relación esencial entre los vivos y los que ya no están.

En la producción arquitectónica funeraria actual, las obras que constituyen un referente, son obras en las que sin alusiones iconográficas directas e inmediatas, subyace un respetuoso y meditado sentido metafórico que nace de la propia arquitectura. Buscan nuevas relaciones y nuevas alegorías relacionadas con el retorno a la naturaleza o el transcurrir del tiempo. Han desaparecido las cruces, las antorchas invertidas o los relojes de arena, y estas metáforas han sido sustituidas por sutiles juegos de luces y sombras, por reflejos en planos de agua o por el empleo de formas arquetípicas redefinidas.

\section{NUEVOS ESPACIOS, NUEVAS METÁFORAS}

Dado que los ejemplos más recientes de arquitectura para la muerte no son específicamente cementerios sino tanatorios y crematorios, resultado de que la cremación está asentándose cada vez más, asociada a las ideas de depuración y asepsia, a la esencia y a la mutación, nos detendremos en dos de ellos como muestra de lo expresado: el crematorio Treptow en Berlín (Alemania) y el Kakamigahara en Gifu (Japón).

\section{El bosque}

Ya finalizando el siglo XX, una referencia obligada es el crematorio Treptow (1996/98), obra de Axel Schultes y Charlotte Frank (Fig. 02) por ser uno de los primeros que podemos considerar actuales.
En apariencia se trata de un edificio aséptico, cerrado sobre sí mismo, que se protege, se independiza del entorno y se aleja de retóricas historicistas, sin referencias evocativas que simbolicen la despedida, el adiós y el alejamiento que acoge.

A pesar de sus huecos a modo de atrios de acceso, su potente y compacto volumen exterior (Fig. 03) se transforma en el interior en un gran espacio de recepción de planta cuadrada, la sala de la Condolencia, concebido como una estancia hipóstila con sus columnas - que perforan la cubierta y parecen fundirse con ella - dispuestas aleatoriamente sin una regla compositiva aparente, y que se ilumina cenitalmente mediante cilindros de luz. De igual modo, la abertura de luz del perímetro que separa los paramentos verticales de la cubierta, potencia y acentúa la sombra del suelo y desmaterializa el espacio.

Este gran atrio puede ser interpretado como una metáfora del bosque (Fig. 04), con sus troncos como pilares cósmicos cuyas copas dejan pasar la luz que se filtra desde lo alto. "Cuando estamos en un bosque nos medimos con los árboles; la relación de tamaño que se establece entre ellos y nosotros y entre ellos y entre sí nos ayuda a medir el espacio» ${ }^{8}$. La fuerte y potente materialidad de las columnas y del espacio evoca, por contraposición, a otra metáfora del bosque como es la ingrávida sala del Paraíso del memorial dedicado a la figura de Dante, el Danteun de G. Terragni y P. Lingeri, en la que la combinación de estructura y luz plasma la idea de lo etéreo y de lo inmaterial.

Se busca deliberadamente provocar una percepción emocional y expresiva en el usuario a través de la escala; igualmente, el manejo de los juegos de luz y de penumbra recuerda las palabras de Campo Baeza cuando expresa: «La luz es el material básico, imprescindible de la arquitectura. Con la misteriosa pero real capacidad, mágica, de poner el espacio en tensión para el hombre. Con la capacidad de dotar de tal cualidad a ese espacio, que llegue a mover, a conmover a los hombres»?

En definitiva, se trata de un espacio sobrecogedor, de intenso dramatismo, que induce al silencio y a la meditación, que busca una espiritualidad no ligada a credo alguno y una monumentalidad exigida por el contenido y la función que alberga.

\section{El viento y la nube}

Un planteamiento radicalmente diferente al anterior es el del crematorio en el cementerio de Kakamiga- 

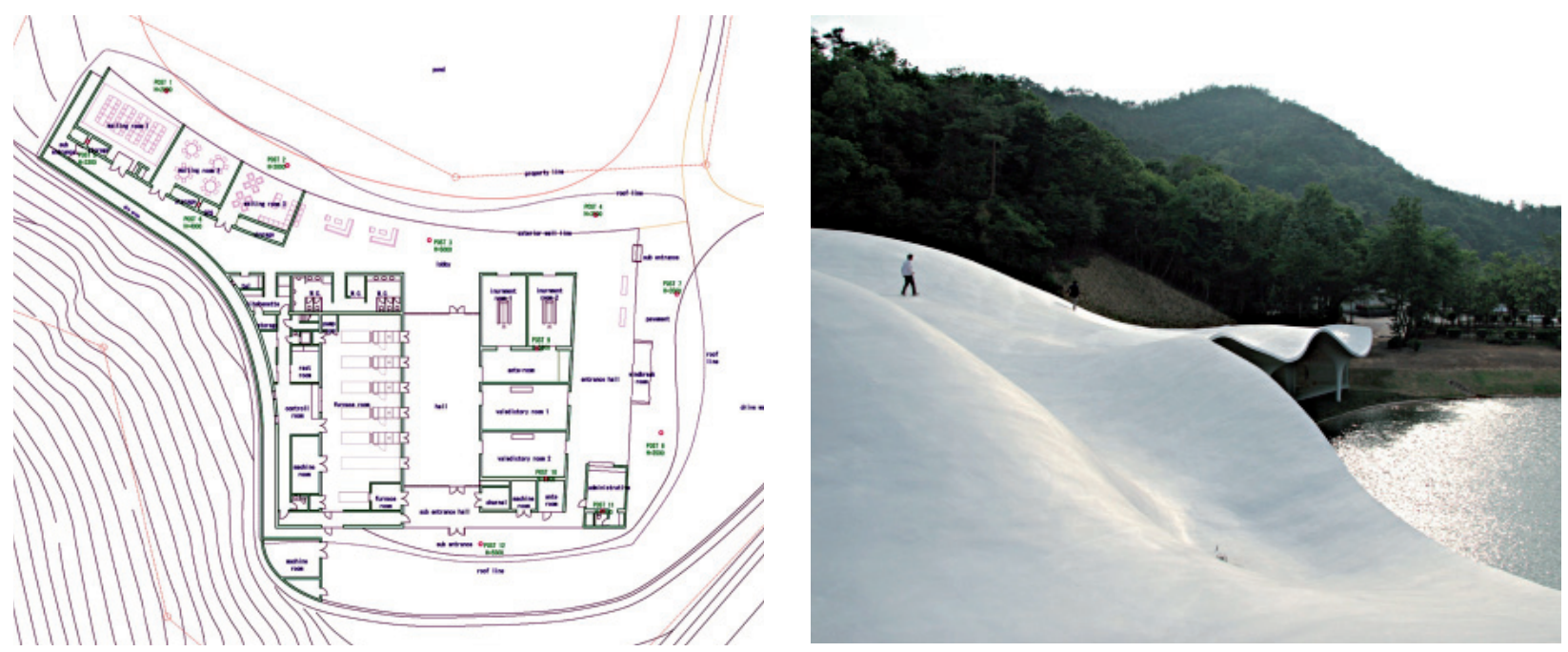

5-6 Toyo Ito, crematorio Kakamigahara, Gifu, Japón, 2004-2006. Planta de situación y vista exterior

hara (2005), ubicado en el lugar de Meiso no mori, o bosque de la meditación, obra de Toyo Ito (Fig. 05).

Frente a la hermética geometría prismática y monumental del crematorio Treptow, éste opone una suave y sutil forma orgánica que huye de lo pesado, busca lo liviano y - en cierto modo- lo etéreo.

El edificio (Fig. 06), ubicado en un «enclave sereno, arropado por montańas con árboles y frente a un estanque» ${ }^{10}$, elementos con valores divinos en la tradición nipona, dialoga con el paisajecircundante; en primer lugar, a través de su ondulada lámina de cubierta a modo de gran nube suspendida que continúa la suave sinuosidad de las colinas de alrededor; y en segundo lugar, esta lámina se prolonga hacia el exterior conformando un porche perimetral, el tradicional engawa o espacio intermedio entre el dentro y el fuera, entre lo artificial, lo construido, y el entorno natural (Fig. 07). Buscando «la densa sombra que reina bajo el alero»" ${ }^{11}$, puesto que mientras la cultura occidental busca la belleza en el juego de la luz, la oriental busca captar el enigma de la sombra. Este edificio se puede considerar como una reinterpretación dela arquitectura tradicional japonesa en la que las cubiertas tienen más peso visual que el espacio inferior; esto se refuerza por el cerramiento acristalado que parece desmaterializar el edificio, potenciando la pregnancia perceptiva de la cubierta ondulada bajo la que se desarrollan todas las funciones propias del crematorio.

Arquitectura etérea, sin apenas aristas (Fig. 08), que actúa a modo de contenedor en cuyo interior se dis- ponen las salas de velar como piezas sueltas quebrantando la sinuosidad del techo «en clave a la tradición de fragmentación-adición, el todo como suma de las partes, que propone en arquitectura una distribución en planta con las líneas de visión rotas; la percepción de la totalidad resulta inquietante» ${ }^{12}$.

La intensa relación mística que mantiene la cultura japonesa con la naturaleza se muestra en este edificio destinado a homenajear y despedir a los muertos. De su consideración de "paisaje construido»" ${ }^{13}$ parten sus connotaciones como espacio de carácter sagrado, puesto que en él la naturaleza alcanza un valor simbólico que la trasciende, que se halla en su interior o que se manifiesta a través de ella ${ }^{14}$.

Se trata de un edificio que busca crear un lugar de paz y abstracción, que hace realidad y materializa las palabras de su autor: «QQué atractivo sería, si existiera, una arquitectura del viento, como un asceta del viento que flota en el aire! $\aleph^{15}$

\section{CONCLUSIONES}

A la concepción occidental del crematorio de Axel Schultes y Charlotte Frank se opone la oriental de Toyo Ito. Dos espacios diferentes, conceptualizados desde la óptica de los sentimientos y de las emociones, expresados sutilmente a través de metáforas ancestrales como el bosque, el viento y la nube, que buscan estimular la sensibilidad del usuario.

En ninguno de los casos se evidencia la utilidad de los 

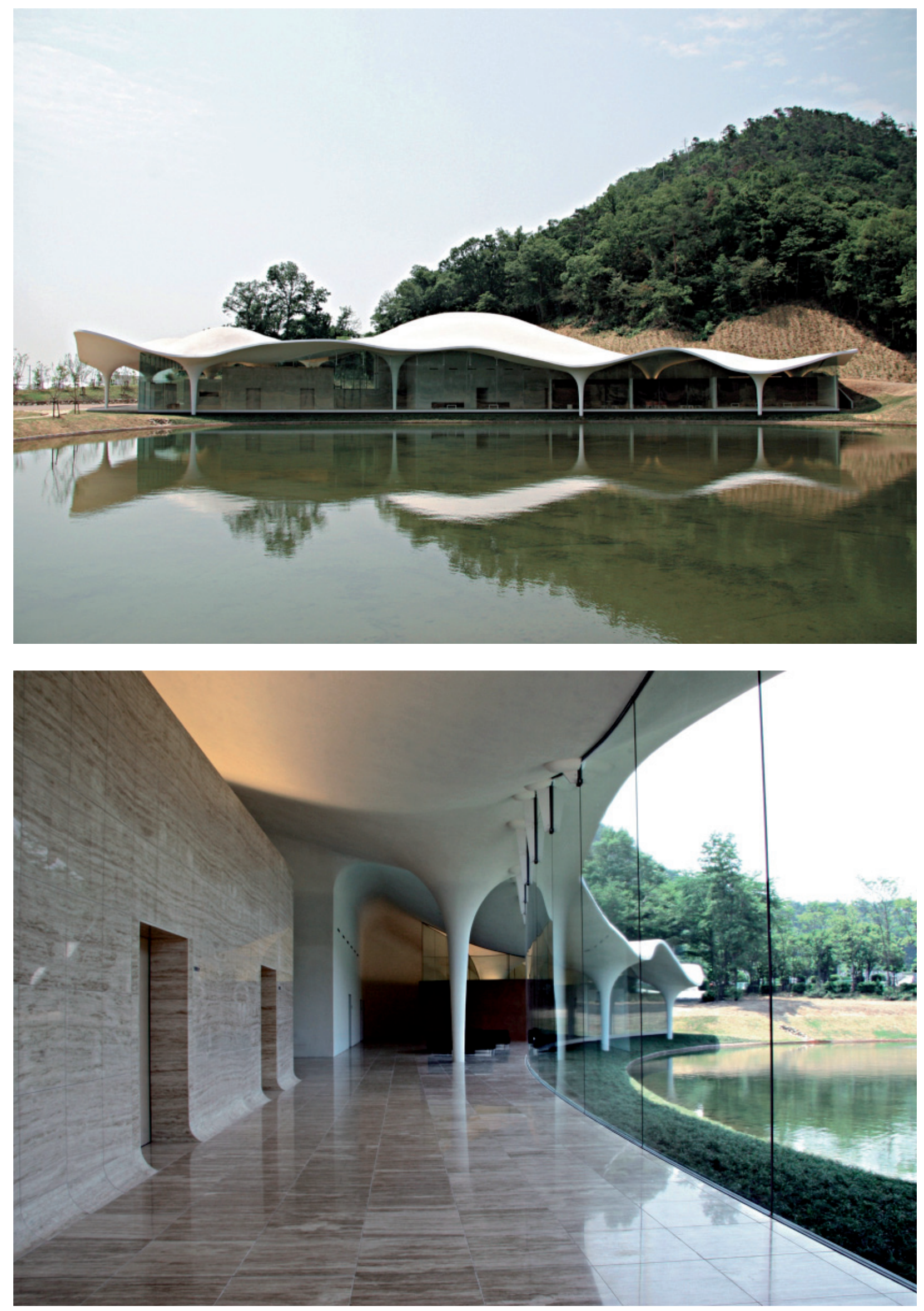

7-8 Toyo Ito, crematorio Kakamigahara, Gifu, Japón, 2004-2006. Vista del exterior y vista del interior 
edificios, pero en ambos, con criterios distintos, se buscan formas arquitectónicas que tratan de invocar estructuras profundas de nuestra espiritualidad, enfrentando lo pesado con lo ingrávido, lo opaco con lo transparente, la sombra con la luz, lo artificial con la naturaleza. Dos ejemplos en los que la arquitectura se transforma en escenario ritual que predispone a la despedida.

Con el análisis realizado en los dos ejemplos elegidos se manifiesta que ambos, desde enfoques diferentes, utilizan recursos metafóricos inherentes a la propia arquitectura. No se hace alusión a la funcionalidad inmediata de los edificios-la despedida, la ausencia o, en definitiva, la muerte-, sino que ésta es tratada como la sociedad actual impone: discretamente y con un cierto misterio. Se trata de arquitecturas con significados ocultos apenas perceptibles, puestas al día desde la perspectiva actual de la muerte, en las que subyace la idea de E.-L. Boullee de que son estos espacios los que más requieren la poesía de la arquitectura. En definitiva, obras en las que se utiliza la metáfora como herramienta conceptual y como recurso de ideación.

\section{Notas}

1. Según los estudios de Carl G. Jung (1875-1961) los símbolos no solo constituyen un lenguaje universal sino que intervienen en el pensamiento y en la conducta humana, desde esta perspectiva definía sus arquetipos, considerándolos como una herencia generalizada de la humanidad. Cf. Carl Gustav Jung, El hombre y sus simbolos (Barcelona: Caralt, 1977), 89-98.

2. Mircea Eliade, Imágenes y símbolos (Madrid: Taurus Humanidades, 1999), 189. El simbolismo va más allá de las limitaciones de la palabra, por lo que resulta un lenguaje sintético de fácil lectura e interpretación, en el que prevalece la asociación sobre la razón. De ahí su recurrente uso en todas las culturas. Véase también: Peter Bonnici, Lenguaje visual. La cara oculta de la comunicación (Barcelona: Index Books, 1998); Román Gubern, Del bisonte a la realidad virtual. La escena y el laberinto (Barcelona: Anagrama, 1996); Geoffrey Broadbent, Richard Bunt, Charles Jencks, El lenguaje de la arquitectura. Un análisis semiótico (México: Editorial Limusa, 1984); o Michael Evamy, Un mundo sin palabras (Barcelona: Index Book, 2003).

3. Mientras que la metáfora aporta una visión desde un punto de vista diferente, un significado imaginario, el símbolo es analogía y asociación (cf. Álvaro Morales Hernández, «La metáfora colectiva. Metodología participativa en la arquitectura y el urbanismo», Urban 7 (2002): 42).

4. Pierre Bonte y Michel Izard, Diccionario Akal de etnología y antropología (Madrid: Akal, 1996), 647.

5. Cf. Antonia María Pérez Naya, "Arquitectura del silencio y la memoria. Análisis de los cementerios de la Costa da Morte gallega» (Tesis doctoral inédita, Universidad de A Coruña, 2007).

6. Nigel Barley, Bailando sobre la tumba (Barcelona: Anagrama, 2000), 61. Este mismo autor califica la muerte como el hecho universal definitivo, evidencia de la universalidad de nuestro mundo.

7. Mircea Eliade, Lo sagrado y lo profano (Barcelona: Paidós, 1998), 23. Eliade expone cómo el ser humano concibe lo sagrado en contraposición con lo profano. Mientras las culturas de la antigüedad estaban totalmente impregnadas y cercanas a lo sagrado, la sociedad actual tiende a vivir en un mundo desacralizado; al menos aparentemente, puesto que todo lo relacionado con la muerte, sus espacios y sus rituales continúan revestidos de carácter sacro.

8. Juan Carlos Anuncio Pastor, Peso y levedad. Notas sobre la gravedad a partir del Danteum (Barcelona: Fundación Caja de Arquitectos, 2007 ), 75.

9. Alberto Campo Baeza, "Esencialidad. Mas con menos (manifiesto)», en Idem., La idea construida. La arquitectura a la luz de las palabras (Madrid: COAM, 1996), 40

10. Toyo Ito, «Tanatorio Municipal Meiso no Mori», El Croquis 147 (2009): 72 . De igual modo la utilización del agua en sentido metafórico se encuentra con frecuencia en obras relacionadas con la arquitectura funeraria. Destaca su uso alegórico en el tanatorio de León, de Jordi Badia Soler y Josep Val Puig; la lámina de agua de la cubierta, con su permanente reflejo del cielo, es una metáfora que predispone para la función que alberga el edificio.

11. Junichiro Tanizaki, El elogio de la sombra (Madrid: Siruela, 2004), 42.

12. Álvaro Varela de Ugarte, "Crematorio de Kakamigahara», Tectónica 25 (2007): 28

13. Mohsen Mostafavi, «Suavizar el rigor de la retícula. La nueva naturaleza de Toyo Ito y el artificio de la Arquitectura», El Croquis 147 (2009): 28.

14. Cf. Natale Spineto, Los simbolos en la historia del hombre (Barcelona: Lunwerg, 2002), 181

15. Toyo Ito, «Hacia la arquitectura del viento», en Idem., Escritos (Murcia: COAT, 2000), 37. El edificio refuerza la idea del autor, para el que la naturaleza está por encima de la arquitectura, que se funde y se moldea con el paisaje.

\section{Procedencia de las ilustraciones}

Figs. 01-08. Archivo de la autora.

\section{Sobre la autora}

Antonia Pérez Naya. Arquitecta por la Universidad de Santiago de Compostela (1984). Doctora Arquitecto por la Universidad de A Coruña (2007). Profesora Titular de Escuela Universitaria de la misma desde 1998, donde imparte docencia dentro del Departamento de Representación y Teoría Arquitectónicas. Miembro del Grupo de investigación en Representación Arquitectónica do Patrimonio (GIRAP). Sus líneas de investigación fundamentales están relacionadas con la arquitectura funeraria. Los resultados de su trabajo han sido publicados en diversas actas de congresos internacionales, y revistas.

antonia.perez.naya@udc.es 